\title{
Study on the influence of soil moisture and plant roots on slope stability of dump
}

\author{
Zhanqi Liang, and Yanping Liu* \\ Department of Water Resources for Pastoral Areas of the Ministry of Water Resources, huhhot \\ 010020
}

\begin{abstract}
Under the background of ecological civilization construction and comprehensive promotion of "green mine" construction in China, for the waste dump formed by a large amount of abandoned soil and slag in the process of mineral resource production, it is one of the important contents of mine ecological restoration to restore and reconstruct the ecology, especially the slope vegetation. Based on the origin of the dump, when rainfall or irrigation water infiltrates into the soil, the physical and mechanical properties of slope soil are changed, and the shear strength of soil is continuously reduced, which has a negative impact on the slope stability. In this paper, we take south mining of DaTang open-pit mine as an example, through field investigation and sampling, laboratory analysis and the computer software analysis method, we set up soil shear strength parameters under different soil water content and different depth of plant roots, using the Slope stability of Slope/W module, establishing the model of slope . Based on limit equilibrium theory to calculate the safety factor, it is concluded that under the condition of the bare Slope stability of Slope soil water safety threshold is $14 \%$. The root system of slope vegetation plays an important role in slope stability, in which the effect of leguminous vegetation on slope stability is obviously better than that of gramineous vegetation. When the soil moisture of slope is $20 \%$, the slope stability coefficient can be increased by $7 \%$.
\end{abstract}

Keywords: Soil moisture; Slope of dump; Overburden layer; Stability.

\section{Introduction}

Under the background of China's ecological civilization construction and promoting the green mines construction comprehensively, we have gradually formed new understanding and new standards for mine restoration, gradually improved and accelerated the pace of controlling. Especially in recent years, the green mines construction has become a normalized and standardized production mode, and finally realized the harmonious coexistence of Mines. Coal mining, especially open-pit coal mining, in the process of production, a large number of waste soil or gangue formed dump which has changed the soil original mechanical composition and structure, resulting in poor water condition, poor soil and low biological activity. Under the action of heavy rainfall, strong wind and gravity, surface erosion, gully erosion, even gravel surface erosion, subsidence, collapse and landslide are very easy to occur.

* Corresponding author: mkslpy@126.com 
Therefore, to restore and rebuild dump ecology has become important content of ecological restoration in mining area. In order to make up for the lack of atmospheric precipitation, water uneven distribution and air in space, it is necessary to carry out irrigation and water supplement in the process of vegetation restoration on the dump slope to ensure the normal growth of vegetation on the slope. In face of the contradiction between slope safety and ecological benefits, it is of great significance to study the safety threshold of soil moisture on the slope stability of dump to ensure the ecological benefits of slope.

Taking the South dump of Datang International Xilinhot open pit as an example, the slope stability of the dump under different soil moisture and vegetation conditions was studied by means of field survey sampling, indoor test analysis and computer software analysis. The stability of the slope soil changes with the shear strength of the soil when the external environment of the dump slope remains unchanged. In this study, the shear strength parameters of soil under different soil moisture content and different plant root depth were set up. Combining with the actual soil texture in the study area, the slope stability model of dump slope with different soil moisture content and different plant root depth was established by using slope stability module. Basing on the limit equilibrium theory to calculate the safety factor, then to analyze the change rule of slope stability under different plant measures or irrigation or precipitation conditions.

\section{Limit equilibrium theory}

The traditional slope stability analysis method is developed from soil mechanics and basic engineering. It is mainly used to evaluate the effectiveness of excavation, highway and expressway embankment, earth dam and flood embankment, natural slope and engineering slope. The method is mainly based on the concept of "limit equilibrium", which defines the limit equilibrium state as that the shear stress in the slope is just equal to the shear strength of the slope material and establishes the limit equilibrium equation through the distribution of shear stress and shear strength on the potential sliding surface. In the stability analysis of soil slope, the limit equilibrium slice method of limit equilibrium theory is usually used to calculate the safety factor of slope stability.

There are many calculation methods for slice method, which are basically similar. The difference lies in whether the assumption and calculation method of the inter strip force and inter strip relationship satisfy the equilibrium equation. The conventional method or Fellenius is an earlier method, which ignores all the inter strip forces and only satisfies the moment balance. Bishop proposed a slice method, which considered the normal force and ignored the shear force. Similarly, Bishop's simplified method only satisfies the torque balance. Janbu's simplified method is similar to Bishop's slice method, which only includes the normal force and ignores the shear force, but it satisfies the static equilibrium in horizontal direction, and also does not satisfy the moment equilibrium equation. The appearance of computer promotes the further development of limit equilibrium method and makes it more rigorous in mathematics.. In this paper, Morgenstern price method is used to calculate the slope stability.

The basic content of the assumption of inter bar force is when the width of the strip is small enough, the joint action point of the sliding surface at the bottom of the strip is considered to be at the midpoint of the bottom surface of the strip. The vertical force between bars is assumed to be a function of horizontal force, i.e. $H=l \operatorname{Pf}(x)$

In the formula, $\mathrm{P}$ is the shear force of the inter strip action. $\mathrm{H}$ is the normal force of the inter strip action and 1 is the weight of the function. The equilibrium conditions for solving equations include the following parts. (1) Horizontal static equilibrium condition is $\Sigma \mathrm{x}=0$. (2) Vertical static equilibrium condition is $\Sigma y=0$. (3) Moment balance condition is $\Sigma \mathrm{M} 0=0 .(4)$ Limit equilibrium conditions are met on the bottom of $n$ soil strips.(5) Overall moment 
balance.

\section{Numerical analysis}

\subsection{Overview of the research area}

The research area is located in the Datang Xilinhot mining open-pit mine in Xilinhot City, Inner Mongolia. The ecological environment of the area is fragile, the climate is dry, the wind is large, and the vegetation degradation is serious. The dump site of the test area is located in the southeast of the mining area, the area is $13.66 \mathrm{~km}^{2}$. It is a stepped layered stacking landform with platform and slope distribution. The relative height difference is $100 \mathrm{~m}$. The slope length of each step is about $20 \mathrm{~m}$. The step slope is covered with soil after the coal gangue is piled, forming a overburden slope with a slope angle from $32{ }^{\circ}$ to $34^{\circ}$. The overburden slope is steep and loose. The characteristic parameters of the dump slope in the test area See Table 1.

Table 1. The table of slope characteristic parameters of dump.

\begin{tabular}{|c|c|c|c|c|c|}
\hline $\begin{array}{c}\text { slope } \\
\text { length } \\
(\mathrm{m})\end{array}$ & $\begin{array}{c}\text { slope } \\
\left({ }^{\circ}\right)\end{array}$ & $\begin{array}{c}\text { soil } \\
\text { thickness } \\
(\mathrm{m})\end{array}$ & $\begin{array}{c}\text { Saturation permeability } \\
\text { coefficient }(\mathrm{mm} / \mathrm{min})\end{array}$ & $\begin{array}{c}\text { bulk } \\
\text { density }\left(\mathrm{g} / \mathrm{cm}^{3}\right)\end{array}$ & $\begin{array}{c}\text { internal friction } \\
\text { angle }\left({ }^{\circ}\right)\end{array}$ \\
\hline 20 & 33 & 0.3 & 0.0306 & 1.45 & 30 \\
\hline
\end{tabular}

\subsection{Slope calculation model}

In the test, the $\leq 2 \mathrm{~mm}$ soil particles screened from the soil samples were remolded. The height of the samples was $2 \mathrm{~cm}$ and the diameter was $5 \mathrm{~cm}$. Each soil sample was divided into five groups according to different water content. When making soil samples, the water content of soil samples shall be strictly controlled according to the test procedures, so that the water content of soil samples is equal to its natural water content, and the water quality to be increased or decreased of the soil samples shall be calculated according to the target water content. If the sample needs to increase the moisture, use a special syringe to drop the increased moisture into the sample. If the sample needs to reduce the moisture, it can make the natural moisture loss, so that the soil moisture reaches the specified design value.

When calculating the stability of the dump slope, the cohesion $\mathrm{c}$ and internal friction angle of the slope must be obtained first. Therefore, the direct shear test was carried out by using the direct shear apparatus to determine the shear strength of the soil. In the experiment, a ring cutter with inner diameter of $60 \mathrm{~mm}$ and height of $20 \mathrm{~mm}$ was used. After each sample was sheared, the shear stress under four different vertical pressures could be obtained. Coulomb formula is $\tau=\mathrm{c}+\sigma \tan \varphi$.

Using shear stress $\tau$ and the corresponding vertical pressure $\sigma$, according to Coulomb formula, the cohesion $\mathrm{c}$ and internal friction angle $\varphi$ of each sample can be calculated The cohesion $\mathrm{c}$ and friction angle pof slope soil under different dry density and water content were obtained in table 2 for details.

\subsection{Slope stability analysis}

When the slope is a bare slope, the scenarios of different soil moisture content of the slope are simulated through the model, and the stability of the slope with soil moisture content of $5 \%, 10 \%, 25 \%, 30 \%$ and $40 \%$ is analyzed. The calculation results of the model are shown in Table 2. The calculation results of the model show that with the increase of soil moisture 
content of the slope, the stability safety factor of the dump slope decreases, indicating that the dump slope begins to collapse become unstable and there is the possibility of landslide.

Table 2. The Setting value of model operation parameter.

\begin{tabular}{|c|c|c|c|c|}
\hline & $\begin{array}{c}\text { soil moisture } \\
\text { content }(\%)\end{array}$ & bulk density $\left(\mathrm{g} / \mathrm{cm}^{3}\right)$ & Cohesion $\mathrm{C}(\mathrm{kPa})$ & $\begin{array}{c}\text { internal friction } \\
\text { angle } \varphi\left({ }^{\circ}\right)\end{array}$ \\
\hline \multirow{3}{*}{$\begin{array}{c}\text { disposal } \\
\text { materials } \\
\text { and } \\
\text { covering } \\
\text { soil }\end{array}$} & 5 & 1.90 & 27.50 & 22.70 \\
\cline { 2 - 5 } & 10 & 1.90 & 21.00 & 20.50 \\
\cline { 2 - 5 } & 25 & 1.90 & 11.50 & 9.20 \\
\hline vegetation & 30 & 1.90 & 10.00 & 8.70 \\
\hline
\end{tabular}

According to the long-term analysis of the soil moisture content of the dump slope, the soil moisture content of slope is generally $5 \%-29 \%$. When the slope is in the state of natural soil moisture, that is, when the soil moisture is $5 \%$, the analysis of the critical slip surface of the slope shows that the safety factor is 1.745 , the slope stability is the best. According to the safety factor in table 3, the slope stability is in the third level and the dump slope tends to be unstable. When the soil moisture content is $25 \% \sim 40 \%$, the calculation results show that the safety factor of the dump slope decreases to 0.777 , indicating that the slope is unstable and prone to landslide.

According to the soil shear strength corresponding to different water content of the dump slope, the stability of the dump slope is analyzed and its safety factor is calculated. It is found that there is a power function relationship between the safety factor of slope stability and soil water content and the fitting equation is $y=4.62 x-0.577, R^{2}=0.94$. From this analysis, we can see that with the increase of soil water content, the slope safety factor decreases significantly. When the soil water content is $14 \%$, it is the safety threshold of slope stability.

\subsection{Effects of different vegetation on slope stability}

The existence of debris plays an important role in controlling soil erosion and shallow landslide, decreasing the soil erosion on the surface of the slope and increasing the stability of the soil on the surface of the slope. with the growth of vegetation, the effect of soil stabilization and slope protection is becoming stronger and stronger. Vegetation not only plays the role of soil stabilization and slope protection, but also plays the role of soil improvement and ecological environment improvement.

When the roots grow in the soil, the roots produce axial pressure to the surrounding soil, which increases the bulk density of the surrounding soil. In addition, there are many forked roots, root nodes and root hairs, which greatly increase the contact area between root and soil. A large number of hairy roots and fibrous roots around the root system have the function of winding, connecting and consolidating the soil particles around the root system. There are a lot of root hairs on the root surface. Root hairs increase the contact between root and soil, and play a role in consolidating and winding the surrounding soil.

The alfalfa plant roots mainly improve the stability of slope protection by improving the soil shear strength. Therefore, combined with the actual situation of the study area, the model shear strength parameter values are set. The main vegetation of dump slope is alfalfa and grass with root length less than $1 \mathrm{~m}$. According to the investigation results of alfalfa and local vegetation growth,we set different root length, under the condition of $20 \%$ soil moisture, the root length of three different plants were set as $0.2 \mathrm{~m}, 0.3 \mathrm{~m}, 0.5 \mathrm{~m}, 0.8 \mathrm{~m}, 1.0 \mathrm{~m}, 1.5 \mathrm{~m}$ and $2.0 \mathrm{~m}$ respectively to analyze the overall stability of slope plants. 


\section{Conclusion}

(1) The power function relationship exists between the safety coefficient of slope stability and soil moisture content, and the fitting equation is $\mathrm{y}=4.62 \mathrm{x}-0.577, \mathrm{R}^{2}=0.94$. That is, with the increase of soil water content, the slope safety coefficient decreases obviously. When the soil water content of slope is $14 \%$, the safety factor of slope stability is 1 , that is, the safety threshold of slope stability is $14 \%$.

(2) Soil water of slope has an important influence on plant growth and slope stability. While vegetation on slope uses the reinforcement and anchorage of root system to improve the shear strength of soil and play a role of soil protection, so as to effectively prevent and control soil erosion on slope. In herbaceous vegetation, legume vegetation has better effect on slope stability than Gramineae vegetation. When the soil moisture of slope is $20 \%$, the slope stability coefficient can be increased by $7 \%$. Therefore, legumes should be firstly considered in the vegetation allocation of slope.

\section{Acknowledgments}

This research was supported by the National Key R\&D Program of China "Eco-security technology for coal mining bases in the Northwestern arid desert regions in China" (2017YFC0504400)-“Studies on the key technologies of water resources protection and comprehensive utilization in mining area" (2017YFC0504405).

\section{References}

1. Shi Ya-qi. China's green mine construction policy and pattern under the new normal [J]. Energy and energy conservation, 2019, 12(171):73-74.

2. Yang Chun-peng. Guidance of green mine construction in the new era $[\mathrm{J}]$, Jilin geology, 2019, 12(171):73-74.

3. Guo Jian-ying, He Jing-li,Li Jin-rong, et al. Influence of artificial reshaped landform in mining area on soil erosion in Xilinguole grassland and its control effect [ $\mathrm{J}]$. Journal of soil and water conservation, 2015, 29(1):56-61.

4. Lv Chun-juan,Bai Zhong-ke, Zhao Jing-kui, et al. Research progress of soil erosion and soil and water conservation in mining area $[\mathrm{J}]$, Journal of soil and water conservation, 2003, 17(6):85-88.

5. Xing En-de, He Jing-li, Zhang Tie-gang, et al. Effects of coal mining on vegetation coverage, biomass, soil moisture and groundwater level around mines, Grassland and Lawn, 2019, 39(04):53-57.

6. Li Jun-chao, Wang Zhan. Study on the measures of soil and water loss prevention and ecological environment control in mining area of western Henan Province [J]. Environment and development, 2018, 5:49-50.

7. Liang Zhan-qi, He Jing-li, Shan Dan, et al. Study on the suitable irrigation method for artificial vegetation restoration on the slope of plastic landform [J]. Soil and water conservation in China,, 2016, 7:57-60.

8. Liu Yan-ping, Liang Zhan-qi, Rong Hao, et al. Study on water saving irrigation technology for slope vegetation restoration of mining dump [J]. Grassland and Lawn,2018, 38(05):49-50. 